Silva, P.; Valente, T.; Sena-Cruz, J.; Azenha, M.; Barros, J. (2017) "Viscoelastic response of an epoxy adhesive for construction since its early ages: experiments and modelling." Composites Part B, 116: 266-277. DOI: 10.1016/j.compositesb.2016.10.047

\title{
VISCOELASTIC RESPONSE OF AN EPOXY ADHESIVE FOR CONSTRUCTION SINCE ITS EARLY AGES: EXPERIMENTS AND MODELLING
}

Patrícia Silva, Tiago Valente, Miguel Azenha, José Sena-Cruz ${ }^{1}$, Joaquim Barros

ISISE, University of Minho, Department of Civil Engineering, Guimarães, Portugal

\begin{abstract}
Epoxy adhesives have been extensively used in strengthening of reinforced concrete structures. In spite of that, research on the viscoelastic behaviour of these adhesives and its influence on the mechanical behaviour of strengthened concrete structures is scarce, particularly at the early ages of curing. The main goal of present work is to better understand the tensile creep behaviour of a specific commercial epoxy adhesive both at early ages and at long term. For this purpose, an experimental program comprising tensile creep tests was performed, in which epoxy specimens were subjected to: (i) equal stress levels but loaded at different ages, and; (ii) two different stress levels for a specific loading age. The results obtained have confirmed the viability of the principles of homogeneity and superposition, thus allowing the classification of this epoxy as linear viscoelastic. In addition, analytical simulations with Burgers model were carried out, and its predictive performance was considered insufficient at early ages, particularly upon unloading. In order to surpass some disadvantages of this model, a new framework is proposed to analytically evaluate the creep curing behaviour of this type of viscoelastic epoxy adhesives. The obtained results evidenced the capability of the proposed framework to predict the creep behaviour of an epoxy adhesive since its early ages.
\end{abstract}

Keywords: Epoxy adhesive; Viscoelasticity; Creep; Early ages; Simulation model.

\footnotetext{
${ }^{1}$ Corresponding author (jsena@ civil.uminho.pt)
} 
Silva, P.; Valente, T.; Sena-Cruz, J.; Azenha, M.; Barros, J. (2017) "Viscoelastic response of an epoxy adhesive for construction since its early ages: experiments and modelling." Composites Part B, 116: 266-277. DOI: 10.1016/j.compositesb.2016.10.047

\section{INTRODUCTION}

In the last three decades, fibre reinforced polymers (FRP) have been increasingly used in Civil Engineering applications through several strengthening techniques with the aim of improving the overall performance of existing structures, namely the load carrying capacity of reinforced concrete (RC) structures [1]. In most of these techniques, such as externally bonded reinforcement (EBR) [2] or near-surface mounted (NSM) [3], the FRP materials are connected to the structural member by using epoxy adhesives, since these are load-bearing materials that can transfer stresses effectively between FRP reinforcements and concrete substrate. The use of structural epoxy adhesives presents some advantageous features such as: (i) stress distribution in the concrete substrate compatible with the strength capacity of the involved materials; and (ii) it avoids the need to use mechanical fasteners that are susceptible to corrosion and require relatively expensive FRP systems capable of supporting the local gradient of stresses introduced by the fasteners $[4,5]$.

Composite structures, such as RC structures strengthened with FRP bonded to concrete with epoxy adhesives, contain materials of different nature that have distinct stiffness and viscoelastic behaviour. According to the literature [5-11], structural epoxy adhesives exhibit relevant creep deformation when subjected to sustained loads, that is strongly influenced by the stress level applied, loading age and the environmental exposure conditions, such as temperature and humidity. Additionally, epoxy endures an important curing process since the instant of mixing, during which there is a very significant development of stiffness and other mechanical properties $[12,13]$. Therefore, the response of the adhesive when a strengthened element is submitted to the service conditions or when it is applied in prestressing systems $[14,15]$ is strongly dependent on its curing state and creep behaviour, which are also particularly influenced by environmental conditions $[11,16]$. Considering that the application of structural epoxy adhesives in Civil Engineering usually induces loading on the epoxy at early stages of its curing process (e.g. earlier than 3 days of curing) and in uncontrolled environmental conditions, the knowledge of early stiffness development [12] and creep behaviour in this early stage context becomes crucial for an adequate understanding of the overall structural behaviour. These issues acquire additional layers of complexity if it is taken into account that strengthening of structures with epoxy bonded reinforcement usually takes place under uncontrolled environmental conditions.

The majority of studies of the time-dependent behaviour of epoxy adhesives applied in strengthening structural applications present in literature are mainly focused in the response of the material at a matured curing state ( 3 to 7 days) $[10,17]$. However, the research reported by Meshgin et al. [18] focused on the study of the creep behaviour of epoxy adhesives at early ages, namely at 1 day of curing. Meshgin et al. carried out an 
experimental study in order to evaluate the response of epoxy at the concrete-FRP sheet interface at 1 and 7 days of curing when subjected to sustained shear stress. The results have shown that specimens with 1 day of curing presented higher ultimate creep deformation than specimens with a long time-before-loading (7 days). In addition, Meshgin et al. also stated a significant creep strain occurring at relatively early times when the stress-to-ultimatestrength ratio was increased. The magnitude of the applied shear stress and time-before-loading were significant factors in the shear creep behaviour of epoxy at the concrete-FRP interface.

Costa and Barros [10] also performed experimental tensile creep tests with an epoxy adhesive, in which they observed considerable deformations in the tested samples due the creep effect during a period of 1000 hours of loading. The specimens were loaded at 3 days of age and submitted to a constant stress state up to $60 \%$ of adhesive's tensile strength, under controlled environment $\left(20^{\circ} \mathrm{C}\right.$ and $\left.60 \% \mathrm{RH}\right)$. The obtained results confirmed that the adhesive could be assumed as a linear viscoelastic material. Madja and Skrodzewicz [17] also performed an experimental program with a commercial epoxy adhesive, in which the ultimate strength was $40 \mathrm{MPa}$, two times higher than the epoxy adhesive tested in the work developed by Costa and Barros [10]. The stress levels applied in the epoxy adhesive tested by Madja and Skrodzewicz [17], were 33, 43, 54 and 65\% of the ultimate strength. In the creep test results nonlinearity of creep strains was observed at the stress levels of 54 and $65 \%$ of the ultimate strength. In the work developed by Costa and Barros [10], in which the ultimate strength of epoxy adhesive was $\sim 21 \mathrm{MPa}$, the stress levels applied were 20,40 and $60 \%$ of the ultimate strength. The creep strain curves of all the tested specimens at different stress levels exhibited similar time dependent evolution, showing a linear viscoelastic tensile behaviour. Based on the results of [10] and [17] it seems that epoxy adhesives with a higher ultimate strength ( 40MPa) start exhibiting nonlinear viscoelastic tensile behavior at lower stress state levels.

Another relevant issue in the context of the creep of epoxy adhesives pertains to the capacity of modelling their behaviour through analytical/numerical approaches that allow the integrated analysis of the intricate stress redistributions that are expected in RC structures strengthened with epoxy bonded reinforcement. Rheological models have been promoted as efficient tools for simulating linear viscoelastic behaviour [18]. These models are usually materialized by means of associations of Hookean springs and Newtonian dashpots that translate the elastic and viscous components of the material's response, respectively [19]. Furthermore, rheological models with agedependent parameters can be used to represent the behaviour of curing materials, such as polymers or concrete [20]. 
In the literature, the rheological models to simulate the creep behaviour of epoxy adhesives are mostly focused on their response at advanced curing states, such as the model proposed by Madja and Skrodzewicz [17]. These authors proposed the Burger's mechanical model to describe the creep behaviour of hardened epoxy adhesive samples cured at ambient temperature. However, this model proposes the values of its parameters be updated according to the stress level, since the adhesive presented nonlinear viscoelastic properties over a wide range of stress [17]. Costa and Barros [21] also modelled the long-term behaviour of a structural epoxy adhesive up to a sustained stress level of $60 \%$ of the adhesive's tensile strength, using a modified Burgers model. The modifications to the model took into account the suggestion of Feng et al. [5], in which the tensile creep strain can be estimated by an exponential function, and also a specific coupling parameter related to moisture adsorption. The modified Burgers model has also been successfully applied by NASA to fit creep strain curves of epoxy adhesives [8].

Despite of the interesting work developed by Costa and Barros [21] and Madja and Skrodzewicz [17], these models were not tested or prepared to simulate the creep behaviour when the epoxy adhesives are loaded at early ages of the curing process. Indeed, such models lack to consider the curing effects of the material along time, which are of paramount importance at the early stages of curing.

In the work performed by Meshgin et al. [18], another rheological model was proposed but for creep shear deformation of epoxy adhesive at the concrete-FRP interfaces loaded at 1 and 7 days of curing. This model suggested a modification of the Maxwell model because it is composed by this one and a spring in parallel. The authors developed some equations for modelling the parameters used in this model as function of applied shear stress and the time-before loading. However, the parameters used in these equations were shown to be dependent of the loading age. In the model proposed by Meshgin et al. [18], the principle of linear superposition of strain was also considered to simulate the behaviour in the unloading stage. The unloading stage was considered by application of same stress level, but with negative magnitude. The total deformation in the unloading stage was obtained by the summation of the long-term deformation during the loading phase and the unloading long-term deformation at the unloading phase. The results obtained by the proposed model simulated appropriately the longterm creep behaviour of epoxy adhesive at the concrete-FRP interfaces for loading and unloading stages. It is noteworthy that simulation of this unloading stage is of fundamental importance to attain accurate calculations of stresses and strains when modelling FRP strengthened structures in service, due to the long-term response of the epoxy adhesives when submitted to reversible loading and unloading conditions. 
Taking into account the research gaps identified above, the present work aims to assess the tensile creep behaviour of a commercially available structural epoxy adhesive currently used in the context of retrofitting concrete structures, with specific focus on the early ages of the curing process. Even though the usual setups of FRP-adhesive-concrete strengthening systems mostly induce shear stresses in the adhesive, the current research was focused in tensile creep behaviour. This choice was motivated by the simpler testing and analysis procedures, which can represent an important asset when interpreting further testing of creep of the adhesive in shear stress states. A specifically driven experimental program was devised, comprising tensile creep tests. Two main issues were addressed: (i) initially the epoxy specimens were submitted to the same level of stress but applied at distinct loading ages to assess the effect of curing; (ii) additionally, two more specimens were submitted to a higher stress level at 7 days of age, to confirm the linearity of the viscoelastic behaviour.

Based on the experimental results obtained, the performance of the Modified Burgers Model [21] was assessed, highlighting the inherent limitations of such approach in the context of the viscoelastic behaviour of the epoxy adhesive at early ages. In view of the identified shortcomings, a new modelling approach to this phenomenon is proposed, based on a generalized Kelvin Voigt model with aging chains. The performance of this alternative modelling framework is assessed, demonstrating an adequate predictive performance at early ages, both on loading and unloading processes. The modelling parameters obtained through this framework are adequately suited for numerical simulation through readily available structural analysis software (generalized Kelvin chain with aging), and has the interesting feature of allowing quite feasible behavioural estimates at loading ages that were not part of the initial set of data used for fitting.

\section{EXPERIMENTAL PROGRAM}

\subsection{Material - epoxy adhesive}

The structural epoxy adhesive studied in the present work is produced by S\&P® Clever Reinforcement Company and its trademark is "S\&P Resin 220 epoxy adhesive". This epoxy adhesive is a solvent free, thixotropic and grey two-component mix (Component $\mathrm{A}=$ resin, light grey colour; Component $\mathrm{B}=$ hardener, black colour). According to the chemical composition described in the datasheet provided by the manufacturer [22], component A contains Bisphenol A (20\% to 25\%) and Neopentyl glycol diglycidyl ether (5-10\%), whereas the Component B includes Poly (oxypropylene) diamine (20\% to $25 \%$ ), Piperazine (1\% to $2.5 \%$ ) and 3.6-diazaoctanethylenediamin and Triethylenetetramine (20\% to $25 \%$ ). The same datasheet indicates that the homogenized compound density after mixing the two components is 1.70 to $1.80 \mathrm{~g} / \mathrm{cm}^{3}$ and presents the following mechanical properties, attainable after 
3 days of curing at $20{ }^{\circ} \mathrm{C}$ [22]: (i) compressive strength $>70 \mathrm{MPa}$; (ii) tensile E-modulus $>7.1 \mathrm{GPa}$; (iii) shear strength >26 MPa; (iv) adhesive tensile strength to concrete or CFRP laminate >3 MPa.

\subsection{Specimens, test setup and procedures}

The tested specimens were manufactured according to standard ISO 527-2:2012. The geometry of the specimens is depicted in Figure 1a: $4 \mathrm{~mm}$ of thickness, $10 \mathrm{~mm}$ of width in the region of interest, and $115 \mathrm{~mm}$ of clear distance between grips. The specimens were cast into Teflon moulds, inside a climatic chamber at $20^{\circ} \mathrm{C}$ of temperature and $55 \%$ of relative humidity.

In order to assess the mechanical properties of the hardened adhesive, monotonic direct tensile tests were carried out according to standard ISO 527-1:2012, in 35 specimens tested at several ages, coincident with the ages of loading for creep testing. The monotonic tests were performed in a universal testing machine under displacement control, at a rate of $1 \mathrm{~mm} / \mathrm{min}$, according to EN ISO 527-1:2012. The applied load was registered through a load cell with a maximum admissible load of $10 \mathrm{kN}$ (HBM S9M Force Sensor: linearity error less than $\pm 0.05 \%$ F.S.). The thickness and width of the test specimens were measured with a digital caliper (0.01 mm precision) in the three distinct sections (A, B and C as identified in Figure 1a). Based on such measurements, the average crosssectional area was determined to allow the accurate calculation of the longitudinal tensile stress applied to each specimen. The axial strain at mid-height of each specimen was measured with a TML strain-gauge (SG) type BFLA-5-3-3L (5 mm of measuring gauge length). The Young's modulus was calculated with basis on the stressstrain curve obtained in the monotonic tensile tests, as the slope of the secant line between strain values of $0.05 \%$ and $0.25 \%$, according to the recommendations of ISO 527-1:2012. Five samples were tested with this procedure for each of the selected loading ages of the creep tests.

In the monotonic direct tensile tests, the labelling of the specimens shown in Table 1 was performed according to the following mask DT_DN, where DT stands for 'direct tensile test' and DN stands for the actual age of testing (in days) that can take the value $\mathrm{N}=1,2,3,7,57$ and 85 . The DT_D57 and DT_D85 specimens were monotonically tested up to the failure in the unloading ages of the specimens submitted at different stress levels in creep tests. In order to distinguish the tensile tests performed at the 7 days of the specimens subjected to a stress level of $30 \%$ and $40 \%$, the suffixes "(C30)" and "(C40)" was added to the initial denomination. It is noted that it was necessary to perform three different mixtures of epoxy adhesive in order to produce all the specimens. The three mixtures were prepared with components A and B obtained from the same container. 
The experimental program includes six specimens submitted to constant tensile stress in order to study creep behaviour. The creep tests were carried out in the same climatic chamber mentioned above $\left(\mathrm{T}=20^{\circ} \mathrm{C}\right.$; $\mathrm{RH}=55 \%$ ). The main differences between the several creep tests regard the loading ages and the applied stress level. Four specimens were submitted to a constant stress level of $30 \%$ of the maximum ultimate load at their corresponding ages of testing, namely, 1, 2, 3 and 7 days. The other two specimens were loaded at 7 days of age at $40 \%$ of their ultimate load. These stress levels were chosen considering the expected stress levels at the service stage of strengthened structures (based in the work developed by Correia et al. [23]), and the range of stresses where the viscoelasticity response of the present epoxy is expected to be linear.

Table 1 also includes the specimens used in the creep tests. The specimens were named according to the following mask CYY_DN_I, where the variables are: YY standing for the stress level to which the specimen is subjected (in percentage of the ultimate load capacity at the age of testing), and may assume the value 30 or 40 ; $\mathrm{N}$ corresponding to the age of load application (in days) that can take the value $\mathrm{N}=1,2,3$ or 7 ; I is an index to distinguish only equal specimens tested in the same conditions, and it may take the char A or B. For example, the designation C40_D7_A stands for a creep test with a specimen subjected to a stress level of $40 \%$ of its ultimate strength (C40) applied at the $7^{\text {th }}$ day of curing (D7) on specimen A of this type.

The creep tests were carried out using a mechanical system based on a lever structure [18, 24], where the specimens were subjected to constant stress through application of gravity loads (Figure 1). The length of the lever is on the side of the specimen is $L_{s}=125 \mathrm{~mm}$, whereas the lever length at the side of the gravity load is $L_{w}=375 \mathrm{~mm}$, as can be seen in Figure 1d. The creep specimens were instrumented with two strain-gauges (type TLM BFLA-53-3L), glued at the middle height of the specimen, in opposite faces as shown in Figure 1b, and connected to NI Compact DAQ system, which comprised NI 9235 strain-gauge modules for data acquisition. The data was acquired at frequency of $1 \mathrm{~Hz}$ during the first hour of loading, followed by one record per minute during 2 hours, and finally one record every 10 minutes until the end of the test.

After knowing the ultimate strength of the epoxy resin at each loading age, dead weights were chosen and the specimens were carefully loaded (see Figure 1c). For each tested specimen, the measured average crosssectional area $(A)$ was considered and the corresponding applied stress $(\sigma)$ was defined, based on a predefined percentage of its ultimate strength. The mass (gravity load) applied to each sample $(M)$ had been calculated based in Eq. (1), where $g$ stands to the gravitational acceleration.

$$
M=\frac{\sigma \cdot A}{L_{w} / L_{s} \cdot g}
$$


The duration of the creep tests was a maximum of 57 days (1370 hours) in the case of the specimens loaded at $30 \%$ of their ultimate tensile strength $\left(f_{u l t}\right)$. Afterwards, such specimens were unloaded and the creep deformation recovery was monitored during the following 75 days (1800 hours). In the case of C40_D7_A and B, the specimens were loaded during, approximately 85 days (2040 hours) and the recovery period had a short duration of 8 days (192 hours). The creep tests duration is in compliance with the period of time recommended for creep assessment of generic plastics materials defined by ISO 899-1:2003 [25] and ASTM D 2990-09 [26], which is about 42 days (1000 hours).

\section{RESULTS AND DISCUSSION}

\subsection{Tensile mechanical properties}

Figure 2 plots the stress-strain curves obtained at various ages for the specimens tested in monotonic direct tension in the context of the instants of loading and unloading of the specimens, whereas Table 2 includes the main properties obtained in these tests, namely, elastic modulus $\left(E_{a d h, d}\right)$ at different testing ages $(d)$ and ultimate strain $\left(\varepsilon_{u l t}\right)$. As the creep tests of $\mathrm{C} 30$ and $\mathrm{C} 40$ were performed at different periods of time, the direct tensile tests were plotted in two distinct graphs.

In Figure 2 it is possible to observe the evolution of the curing process of the epoxy adhesive through the increase of stiffness at different ages that is evidenced by the different slopes of the curves. The rate of stiffness increase was lower between 3 and 7 days of age when compared with the increase denoted between 1 and 3 days of age. From this data is possible to verify that the major part of curing reactions had already occurred by the age of 3 days. As can be seen in Table 2, this effect was noted in the values of Young's modulus, since $E_{a d h}$ at the age of 3 days was almost twice as much as the value registered at 1 day of age, while the tensile strength only increased $21 \%$. These observations indicate that for this type of epoxy adhesive, the evolution of its tensile strength was faster than its stiffness at early ages. These trends are coherent with those reported by Michels et al. [14], as well as those obtained by Moussa et al. [13] for curing temperature of $22^{\circ} \mathrm{C}$ and $25^{\circ} \mathrm{C}$, respectively. More experimental work is necessary to clarify this difference in kinetics, together with specific insights into chemical/microstructural development of the material.

In order to have a descriptive equation of the evolution of the Young's modulus of this epoxy with time, the empirical-based equation proposed by Silva et al. [27] was deployed. This mathematical equation was already 
applied in the field of epoxy adhesives [12] and is based on existing approaches for predicting the concrete Young's modulus evolution:

$$
E_{\text {adh,num }}=a \cdot \exp \left[-\frac{1}{2} \cdot\left(\frac{\tau}{t}\right)^{\beta}\right]
$$

where $a$ is the Young's modulus value at the end of the curing process (in GPa), $\beta$ is the reaction shape parameter, $\tau$ is the reaction time parameter and $t$ is the age of specimens (in hours). The values of these parameters were obtained by regression analysis by best fitting the experimental results using the method of least squares: $(a, \beta, \tau)$ $=(8.532,1.976,30.977)$. The last column of Table 2 indicates the results obtained using these values in Eq. (2) $\left(E_{a d h, n u m}\right)$, where a good estimate of Young's modulus can be confirmed $\left(r^{2}=0.9636\right)$.

\subsection{Creep behaviour}

Considering the results obtained from the monotonic direct tensile tests, the mass to apply to the specimens for creep testing was determined through Eq. (1). Since it was not possible to exactly apply the predefined stress level with the available masses at the laboratory, stress values close to the expected ones were actually applied. In Table $3 M_{\text {applied }}$ is the mass experimentally applied, $\sigma_{\text {instal }}$ is the corresponding normal stress, and $\% f_{u l t}$ is the exact percentage of the ultimate tensile strength applied to each tested specimen.

Figure 3 shows the evolution of deformation during the creep tests of the specimens loaded at $30 \%$ of $f_{u l t}$ at different ages, and the recovery stage after unloading. The values of elastic strains calculated based on the Young's modulus obtained from monotonic tensile tests at the different loading ages (see Table 2) were marked with points in the same figure (represented as $\Delta \sigma / E_{\text {adh, }}$ ). These values were very close to the elastic strains measured in the creep experimental tests $\varepsilon_{\text {elast,exp }}$, as it may be confirmed through the coincidence of the marked points and the size of the vertical branches of loading/unloading in Figure 3.

In Figure 3b, which depicts the initial instants that followed the loading stage for specimens C30_D1, C30_D2 and C30_D3 as a function of the logarithm of time, it is possible to highlight the significant creep strain that occurs at relatively early ages (until 100 hours $\approx 4$ days), particularly within few minutes after load application. The evolution of creep strain of specimen C30_D1 was quite considerable up to ages of about 3 days. In fact, curing reactions of the material were still under clear development during this period and the creep deformation of this specimen was significantly higher than the specimens loaded at older ages. The creep coefficient was defined as the ratio between the increment of creep strain at time $t,\left(\varepsilon_{\text {total }}(t)-\varepsilon_{\text {elast,exp }}\left(t_{0}\right)\right)$ and the 
instantaneous elastic strain $\mathcal{E}_{\text {elast, exp }}\left(t_{0}\right)$ at the instant of loading $\left(t_{0}\right)$. The creep coefficient was determined for a period of time of 49 days because it was the common period for all specimens loaded at the ages of $t_{0}=1,2,3$ and 7 days and had the values of 4.1, 2.1, 1.9 and 1.3, respectively. As expected, the creep coefficient has decreased with the increase of the age of loading.

Figure $3 \mathrm{a}$ also shows that, at the instant of unloading, the elastic strain was totally recovered considering the Young's modulus determined in the tensile tests at the same age at which the unloading process took place (see Table 2). Afterwards, the kinetic of recovery behaviour of all tests was quite similar, with recovery still ongoing at ages of $\sim 130$ days (end of the experiment).

Figure 3a still evidences that the post-unloading behaviour is directly dependent of the age of loading, i.e., specimens loaded at earlier ages presented higher viscoelastic deformations than the specimens loaded at later ages. This fact is related with the formation of new cross-links of the polymer chains when the specimens were loaded at early ages. Notwithstanding, the achieved equilibrium state did not prevent the evolution of the Young's modulus and the tensile strength of the epoxy adhesive over the time since the post-unloading phase of all specimens were very similar. This corroborates that the polymer chains when the specimens were loaded were not the same when they were unloaded.

Figure 4a plots the measured strains of the specimens C40_D7_A and C40_D7_B, loaded at 7 days of age submitted to a constant stress $\left(40 \%\right.$ of $f_{u l t}$ ), and the recovery after unloading. In the same figure, it is possible to note the good coherence between specimens A and B (same type of specimen at the same conditions), which confirms the repeatability of the materials produced and testing procedures. The values of elastic strains calculated based on the elasticity modulus obtained in monotonic tensile tests were once more consistent. As expected, after unloading (at the age of 85 days), the elastic strain was practically recovered, as shown in Figure 4a.

The same data of Figure 4a is represented in Figure 4b, with the strains normalized to the stress level applied in the specimen, resulting in the so-called 'creep compliance' versus time curves. Additionally, the creep compliance of the specimen loaded at $30 \%$ of $f_{u l t}$ at the same age was also plotted. According to the theory of viscoelasticity, the behaviour of a material can be considered homogeneous when the creep deformations are linearly proportional to the applied stress [9]. In such case, the creep compliance curves obtained for a given loading age (i.e. creep deformations divided by the applied stress) should be equal regardless of the applied stress. The experiments at $30 \%$ and $40 \%$ of the ultimate stress represented in Figure $4 \mathrm{~b}$ have confirmed the homogeneity of the viscoelastic behaviour of the tested epoxy in this range of stress levels. 


\subsection{Modelling creep behaviour - Modified Burgers model}

The initial approach to the modelling of the creep behaviour observed in the previous section consisted in applying the Modified Burgers Model according to the strategy used by Costa \& Barros [21]. In this model the timedependent strain can be expressed according to equation (3):

$$
\varepsilon(t)=\frac{\sigma}{E_{M}}+\frac{\sigma}{\eta_{M}} t+\frac{\sigma}{E_{k}}\left(1-e^{-\left(\frac{E_{k}}{\eta_{k}} t\right)^{1-n}}\right)
$$

where, $E_{M}$ is Maxwell's elastic modulus, $\eta_{M}$ is Maxwell's coefficient of dynamic viscosity, $E_{k}$ is Kelvin's elastic modulus, $\eta_{k}$ is Kelvin's coefficient of dynamic viscosity and $n$ is a coupling parameter related to moisture absorption. The procedure for calculating the parameters of the Modified Burgers model, $E_{M}, \eta_{M}, E_{k}, \eta_{k}$ and $n$ was the same adopted by Costa and Barros [10], and it is omitted here for the sake of brevity.

The parameter fitting procedure was initially solely focused in the initial stage of sustained loading of series C30 (comprising specimens C30_D1, C30_D2, C30_D3 and C30_D7 and their data until the age of 57 days). Inherently to the characteristics of the model, the fitting process had to be done independently for each of the loading ages, for which a distinct set parameters was obtained as shown in Table 4. It is nonetheless remarked that the obtained parameters were quite adequate for the description of the actually observed creep behavior, as shown in Figure 5, with excellent fittings being obtained up to the age of $\sim 57$ days (set of data that was actually used for the fitting). Even though the capacity of this Modified Burgers model to adequately fit the available creep data, which confirms the feasibility claimed in [21], its mere basic assumptions carry an important drawback for the use in structural analysis of the behaviour of RC strengthened systems, which is described next.

In fact, the adequate performance of the set of parameters obtained through this model/method can only be assured for the loading ages of 1,2, 3 and 7 days, which all have different fitting parameters. If the numerical simulation on the structural analysis demands for distinct ages of loading, or even a continuously changing load (e.g. the case of restrained deformations), there is no way of getting creep fitting parameters for intermediate loading ages from those that had been tested, thus rendering the approach Modified Burgers Model almost unusable in such context.

In spite of the shortcoming identified above, the performance of the approach based on the Modified Burgers Model was further tested to evaluate its capacity to describe the unloading events that occur by the age of $\sim 57$ days in the experiments. As this matter had not been addressed in the work of Costa \& Barros [21], an extension to their approach was made with basis on the superposition principle. According to Findley et al. [28], 
when the stress state is removed at $t_{1}$ in viscoelastic materials, the recovery with Burgers model can be obtained from the superposition principle [28], depicted in the introduction. Therefore, an attempt was made to predict the creep behaviour in the unloading and recovery phase of deformation using the same model parameters fitted in the loading phase. The corresponding results are plotted Figure 5, in the period from $\sim 57$ days onwards, and the performance is clearly inadequate, with strong overestimations of the recovery of elastic deformation upon unloading. This was expectable, as the fitting parameters for the unloading were the same as those that had been used for the loading stage, which had occurred at an earlier stage of curing in which stiffness was much lower and tendency to creep was much higher. Therefore, the deficient capacity of the modelling approach to describe the actual measured strain upon unloading tends to be worse for cases in which the initial loading had been applied earlier. It becomes then evident that any attempt to improve the fitting of the strains upon unloading would demand for an entirely new set of parameters for the creep model in the unloading branch. Once again, this is a highly undesirable situation in the context of deriving models and parameters for the numerical simulation of strengthened RC structures that might endure loading/unloading events at arbitrary ages.

\section{PROPOSED MODELLING APPROACH}

\section{General considerations and description of the modelling approach}

The shortcomings identified for the Modified Burgers model led to the necessity of exploring alternative approaches for creep modelling of epoxy adhesives with the two following main requisites/improvements: (i) the modelling approach should allow a single set of parameters to adequately simulate the behaviour at all loading ages and even allow feasible estimates in ages of loading that were not used in the fitting process; (ii) the modelling approach should be able to adequately cope with unloading events without the need for specific fitting processes for such purpose.

After an initial exploratory stage in which several existing models were tested (e.g. the Double Power Law [29], the MC1990 [30] and among other models ), the authors reached the conclusion that the intended requisites should be well satisfied through the use of a Generalized Kelvin Model with aging chains [31]. The Generalized Kelvin Model, shown schematically in Figure 6, is composed by a number of Kelvin elements in series, with a free spring in series, which can be used to represent the creep of a cross-linked material [19]. More information about the general concepts of Generalized Kelvin chains can be found in [9].

Such generalized model has been applied by Bažant and Osman [29] in the context of concrete creep, who proposed a Dirichlet series approximation of the Double Power Law for simplifying the describing process of the 
aging Kelvin chains. The modelling strategy of Bažant and Osman contemplates the effect of curing on the creep behaviour by considering the time dependence of the moduli of the Kelvin chains and of the modulus of the free spring. The proposed framework is based on the model developed by Bažant and Osman, and formulates the creep compliance in view of the elements of the Kelvin chain according to the following expressions:

$$
J\left(t, t_{0}\right)=\frac{1}{E\left(t_{0}\right)}+\sum_{\mu=1}^{N} \frac{1}{E_{\mu}\left(t_{0}\right)}\left(1-e^{-\frac{\left(t-t_{0}\right)}{\tau_{\mu}}}\right)
$$

For $\mu<N$

$$
\frac{1}{E_{\mu}\left(t_{0}\right)}=b_{\mu}\left(\frac{\tau_{1}}{0.002}\right)^{\eta_{\mu}} \frac{\varphi_{1, \mu}}{\lambda \cdot E_{0}\left(t_{0}\right)} 10^{n_{\mu}(\mu-1)} t_{0}{ }^{-m_{\mu}}
$$

For $\mu=N$

$$
\frac{1}{E_{N}\left(t_{0}\right)}=1.2 \times b_{N}\left(\frac{\tau_{1}}{0.002}\right)^{\eta_{N}} \frac{\varphi_{1, N}}{\lambda \cdot E_{0}\left(t_{0}\right)} 10^{n_{N}(N-1)} t_{0}{ }^{-m_{N}}
$$

where $b_{\mu}, n_{\mu}, \varphi_{1, \mu}$ and $m_{\mu}$ are the defining coefficients of the model; $N$ is the number of Kelvin chains; $\tau_{\mu}$ is the retardation time of the $\mu^{\text {th }}$ Kelvin chain; $E\left(t_{0}\right)$ is the modulus of the isolated spring of the Kelvin generalized model, and $E_{\mu}\left(t_{0}\right)$ is the modulus of each Kelvin chain.

While in the original model proposed by Bažant and Osman, the coefficients $b_{\mu}, n_{\mu}, \varphi_{1, \mu}$ and $m_{\mu}$ are fixed for all Kelvin chains, the framework proposed in this paper, henceforward referred as ACC framework, uses different values for these coefficients in each Kelvin chain. Additionally, the ACC framework considers the mathematical equation for Young's modulus forwarded in Section 3.1 (Eq. (2)). In this way, the modulus of the isolated spring of the Kelvin generalized model is determined considering the following expression:

$$
E\left(t_{0}\right)=\lambda \cdot E_{0}\left(t_{0}\right)
$$

where $\lambda$ can take values from 1.2 to 2.0. In this case, the value adopted was 1.5 as recommended in [32].

To obtain the creep functions of the viscoelastic epoxy adhesive, a nonlinear least square method (NLSM) was applied to the experimental creep compliance curves to determine the defining coefficients of the ACC model grouped in the vector $\underline{\psi}=\left\{b_{\mu} ; n_{\mu} ; \varphi_{1, \mu} ; m_{\mu}\right\}$. This fitting procedure considers the following input data: number of Kelvin chains $N$, the retardation times $\tau_{\mu}$, the Young's modulus function $E_{0}\left(t_{0}\right)$, and factor $\lambda$. The number of Kelvin chains should be adequately selected, so that their corresponding retardation times cover the entire scale of 
simulation [33]. It is further noted that, according to Bažant and L'Hermite [33], the retardation times are usually spread uniformly over the logarithmic time scale.

The objective function of the NLSM takes the following form:

$$
\Phi=\sum_{i=1}^{L} \sum_{j=1}^{M_{L}}\left(J\left(t_{j, i}, t_{0, i}\right)-\left(\bar{J}\left(t_{j, i}, t_{0, i}\right)\right)\right)^{2}
$$

where $L$ is the total number of loading ages, corresponding to the number of creep functions to be fitted; $M_{L}$ is the number of discrete points considered for fitting each creep function at the loading age (from experimental data), $\bar{J}\left(t_{j, i}, t_{0, i}\right)$ are the experimental values of the creep functions corresponding to the loading age $t_{0, i}$ for each time step $t_{j, i} ; J\left(t_{j, i}, t_{0, i}\right)$ are the creep functions estimated values determined according to equations (4-7). The meaning of variables $L$ and $M_{L}$ is exemplified in Figure 7 for an illustrative case. The number of discrete points $M_{L}$ should be enough to accurately capture the trend of each creep function. The coefficients of the model can be obtained through the minimization of the following the expression:

$$
\begin{gathered}
\frac{d \Phi}{d \underline{\psi}}=0 \\
\underline{\psi}=\left\{b_{\mu} ; n_{\mu} ; \varphi_{1, \mu} ; m_{\mu}\right\} \quad \mu=1,2, \ldots, N
\end{gathered}
$$

The proposed framework was implemented in MATLAB [34], resorting to the Trust-Region-Reflective algorithm available in this software (function lsqnonlin). Table 5 presents a brief outline of the developed algorithm to determine the defining coefficients of the model. The algorithm has three stopping conditions: (a) the value of $\Phi$ is less than a predefined tolerance $\left(T O L E R_{1}\right)$; (b) the variation of the model coefficients between consecutive iterations is less than a predefined value tolerance $\left(T O L E R_{2}\right)$; (c) the maximum number of acceptable iterations is reached $(M A X I T E R)$. In the present analysis the values of $T O L E R_{1}=1 \times 10^{-12}, T O L E R_{2}=1 \times 10^{-8}$ and $M A X I T E R=100000$ were assumed. It is noted that the fitting process to the experimental data of this research reached the stopping condition (a), which is the most desirable one from the point of view of ensuring the best accuracy of the fitting process.

After all the parameters of the ACC model are obtained, it can be used to predict the strain development resulting from any arbitrarily applied stress history (not necessarily constant). For such purpose, the time under loading is divided into steps (e.g. 1 to $k^{\prime}$, and the continuously varying stress may be approximated by a series of 
small stress increments $\Delta \sigma\left(t_{0}\right)$ applied at the end of each time step. According to the principle of superposition [35], the stress-produced strain at time $t$ is obtained by summing the stress induced strains by each stress increment (Eq. 10), and a different creep function $J\left(t_{k \prime}, t_{0, i}\right)$ is computed for each small increment $\Delta \sigma\left(t_{0}\right)$ adopting the proposed analytical model [35].

$$
\varepsilon(t)=\sum_{i=1}^{k \prime} \Delta \sigma\left(t_{0, i}\right) \cdot J\left(t_{k^{\prime}}, t_{0, i}\right)
$$

\section{Application of the ACC framework to the experimental data}

The application of the ACC framework to the experimental data of series C30 shown in section 3.2 is now addressed. Four ages of loading were considered (1, 2, 3 and 7 days), and solely the data pertaining to the initial loading was taken into account for the definition of the modelling parameters (i.e. until $\sim 57$ days). It was nonetheless taken into account that there was an intent to test the performance of the predictive model for the entire period of testing, corresponding to more than 120 days.

The analytical creep function model considered 6 Kelvin chains. The retardation time of the first chain was 0.001 days and the following were consecutively multiplied by a factor of 10 . This allows the resulting model to simulate creep from the short term of $\approx 0.001$ days ( 1.44 minutes) up to the range of the highest retardation time in the $6^{\text {th }}$ chain: 100 days. Factor $\lambda$ was considered as 1.5 , according to the reasoning made before, whereas the $E_{0}\left(t_{0}\right)$ function was directly extracted from the fitting shown right after Eq. (2).

Figure 8 presents a comparison between the creep compliance registered in the experimental tests and obtained from the proposed model up to the age of $\sim 57$ days. The defining coefficients of the analytical model and the Kelvin chains moduli are, respectively, presented in Table 6 and Table 7. It can be observed that the ACC framework yielded a quite adequate simulation of the creep behaviour of the epoxy adhesive for loading ages between 1 and 7 days of curing.

The relaxation spectra (variations of $E_{\mu}$ with $\tau_{\mu}$ ) related to the fitting at various ages is plotted in Figure 9 . The observation of this figure and its underlying data allows to observe that several features that highlight the feasibility of the obtained set of parameters: (i) this evolution is consistent with the representation shown by Bažant and $\mathrm{Wu}$ [33] from which it is possible to corroborate the following remarks: (i) the moduli of the first retardation time are linked to the elastic response of the material at the instant of loading; (ii) from the second retardation time onwards, the moduli of Kelvin chains tend to decrease from the lowest to the highest retardation times; (iii) the 
moduli tends to stabilize in constant values for advanced retardation times (10 and 100 days) and loading ages (7 days) due to the lower deformations by the creep effect; and (iv) the moduli of the Kelvin chain functions proved to be adequately continuous at different retardation times and loading ages.

While keeping the same creep parameters that have just been shown, the simulation of the entire period of creep experiments was done, by extending up to $~ 130$ days. Figure 10 illustrates the comparison between the creep deformation obtained from the creep tests and from the numerical simulations. A very good agreement was attained between the experimental data and the numerical simulation. The numerical model was indeed able to adequately simulate the elastic recovery when the samples were unloaded. Additionally, the subsequent deformation recovery also presented similarities to the experimental results.

The proposed model was also tested in view of its performance when tested at loading ages that do not coincide with the loading ages used in the fitting process. As the available data only pertained to four ages of loading (1, 2, 3 and 7 days), it was decided to omit one of such ages in the fitting procedure and then attempt to use the resulting set of parameters to predict the creep strains at the age which had been omitted in the parameter estimation process. Two distinct evaluation attempts were carried out: (i) evaluate the prediction for the loading age of 7 days for a set of chain parameters obtained taking into account data from the loading ages of 1,2 and 3 days; (ii) evaluate the prediction for the loading age of 3 days for a set of chain parameters obtained taking into account data from the loading ages of 1,2 and 7 days. The response obtained for these two specific evaluations is shown in Figure 11a and 11b, leading to the confirmation that the model can provide adequate predictions for ages that were not used in the fitting process.

\section{CONCLUSIONS}

The present paper intended to contribute for the adequate understanding and description of the creep behaviour of a structural epoxy adhesive used in FRP strengthening applications. An experimental program composed of tensile creep tests was carried out at different loading ages and two different stress levels. Furthermore, analytical simulations with the Modified Burgers model and a newly proposed framework (termed ACC) were performed. From this work the following main observations and conclusions can be pointed out:

(i) The tensile tests of epoxy adhesive at different ages demonstrated a significant increase of the tensile strength up to 3 days of age. The rate of increase of stiffness was slower than that of the tensile strength at early ages; 
(ii) The elastic strains measured in the specimens tested in the creep-rig were coherent with the ones calculated from the data collected from the monotonic direct tensile tests up to rupture;

(iii) The instantaneous deformation endured by the creep test specimens upon removal of the load was consistent with the one expected with basis on the parallel direct tensile tests conducted at the same age;

(iv) The creep strain in the epoxy had larger importance at earlier ages of loading, within the ages of load application 1, 2, 3 and 7 days. Unloading has been performed at ages of $\sim 60$ days, with rather similar unloading behavior being observed among all tested specimens, regardless of the initial loading age. This trend in creep strain behavior was consistent with the tendency of E-modulus to stabilize near its final value (within $0.47 \%$ ) by the age of 7 days;

(v) Even though linear viscoelastic behaviour was observed in this work up to stress levels of $40 \%$, the experimental data does not allow to define an upper bound for the validity of homogeneity (thus linearity) of creep behaviour;

(vi) From the creep tests in which different ages of loading were analysed, the creep coefficient of specimens loaded with $30 \%$ of its ultimate strength at $1,2,3$ and 7 days of age were 4.1, 2.1, 1.9 and 1.3 within a period of 49 days, respectively;

(vii) It was verified that the creep response of the epoxy adhesive comply to the principle of homogeneity, for specimens loaded at $30 \%$ and $40 \%$ of its ultimate strength;

(viii) The analytical simulations with the Modified Burgers model revealed its adequate capability to predict the creep response of epoxy adhesive within its limits of application. However, the parameters of the model are loading age dependent, and cannot be used to predict the creep function of the material for loading ages that are distinct from those that allowed to obtain the parameters (particularly in the early ages, where significant curing reactions are occurring). In addition, the model could not successfully simulate creep recovery;

(ix) A new framework based on the Generalized Kelvin model was proposed. The derived analytical model was described and tested, having shown adequate capability to simulate the creep behaviour of the studied epoxy adhesive since the early ages of the curing process ( 1 day of curing). Additionally, a numerical simulation of the creep tests was conducted, which presented a very good fit to the experimental results in the loading and recovery phase of the creep tests. 


\section{ACKNOWLEDGEMENTS}

This work is supported by FEDER funds through the Operational Program for Competitiveness Factors COMPETE and National Funds through FCT - Portuguese Foundation for Science and Technology under the project FPReDur FCOMP-01-0124-FEDER-028865 (FCT reference PTDC/ECM-EST/2424/2012) and the project VisCoDyn FCOMP-01-0124-FEDER-041751 (FCT reference EXPL/ECM-EST/1323/2013), as well as the project POCI-01-0145-FEDER-007633. The authors also like to thank the S\&P Clever Reinforcement Ibérica Lda. company for providing the material tested in ambit of the present work. The first author wishes also to acknowledge the grant SFRH/BD/89768/2012 provided by FCT. The second author wishes also to acknowledge the grant SFRH/BDE/96381/2013 co-funded by CiviTest-Pesquisa de Novos Materiais para a Engenharia Civil, Lda and by FCT.

\section{REFERENCES}

[1] Pellegrino C, Sena-Cruz J. Design Procedures for the Use of Composites in Strengthening of Reinforced Concrete Structures. State-of-the-Art Report of the RILEM Technical Committee 234-DUC. RILEM State Art Reports. 2015;19.

[2] Hollaway LC, Leeming M. Strengthening of reinforced concrete structures: Using externally-bonded FRP composites in structural and civil engineering: Elsevier; 1999.

[3] Sena-Cruz JB, J.; Bianco, V.; Bilotta, A.; Bournas, D.; Ceroni, F.; Dalfré, G.; Kotynia, R.; Monti, G.; Nigro, E.; Triantafillou, T. Design Procedures for the Use of Composites in Strengthening of Reinforced Concrete Structures: State-of-the-art Report of the RILEM Technical Committee 234-DUC: Springer; 2015.

[4] Sena-Cruz JM, Barros JA, Coelho MR, Silva LF. Efficiency of different techniques in flexural strengthening of RC beams under monotonic and fatigue loading. Construction and Building Materials. 2012;29:175-82.

[5] Feng CW, Keong CW, Hsueh YP, Wang YY, Sue HJ. Modeling of long-term creep behavior of structural epoxy adhesives. International Journal of Adhesion and Adhesives. 2005;25(5):427-36.

[6] Meyers MA, Chawla KK. Mechanical behavior of materials: Cambridge university press Cambridge; 2009.

[7] Schenck SC, Sancaktar E. Material Characterization of Structural Adhesives in the Lap Shear Mode. DTIC Document; 1983.

[8] Smith ST, Hu S, Kim SJ, Seracino R. FRP-strengthened RC slabs anchored with FRP anchors. Engineering Structures. 2011;33(4):1075-87.

[9] Guedes RM. Creep and Fatigue in Polymer Matrix Composites: Woodhead Publishing Limited; 2011.

[10] Costa I, Barros JAO. Creep of structural adhesives : an overview. In: Proceedings of CICE 2012 6th International Conference on FRP Composites in Civil Engineering. Rome, Conference, Conference 2012.

[11] Silva P, Fernandes P, Sena-Cruz J, Xavier J, Castro F, Soares D, et al. Effects of different environmental conditions on the mechanical characteristics of a structural epoxy. Composites Part B: Engineering. 2016;88:5563.

[12] Fernandes P, Granja JL, Benedetti A, Sena-Cruz J, Azenha M. Quality control and monitoring of NSM CFRP systems: E-modulus evolution of epoxy adhesive and its relation to the pull-out force. Composites Part B: Engineering. 2015;75(0):95-103.

[13] Moussa O, Vassilopoulos AP, de Castro J, Keller T. Early-age tensile properties of structural epoxy adhesives subjected to low-temperature curing. International Journal of Adhesion and Adhesives. 2012;35:9-16.

[14] Michels J, Sena-Cruz J, Czaderski C, Motavalli M. Structural strengthening with prestressed CFRP strips with gradient anchorage. Composites for Construction (Aceite para publicação). 2013.

[15] Rezazadeh M, Costa I, Barros J. Influence of prestress level on NSM CFRP laminates for the flexural strengthening of RC beams. Composite Structures. 2014;116:489-500.

[16] Moussa O, Vassilopoulos AP, Keller T. Effects of low-temperature curing on physical behavior of cold-curing epoxy adhesives in bridge construction. International Journal of Adhesion and Adhesives. 2012;32(0):15-22. 
[17] Majda P, Skrodzewicz J. A modified creep model of epoxy adhesive at ambient temperature. International Journal of Adhesion and Adhesives. 2009;29(4):396-404.

[18] Meshgin P, Choi K-K, Reda Taha MM. Experimental and analytical investigations of creep of epoxy adhesive at the concrete-FRP interfaces. International Journal of Adhesion and Adhesives. 2009;29(1):56-66.

[19] Brinson HF, Brinson LC. Polymer engineering science and viscoelasticity: an introduction: Springer; 2008.

[20] Oliveira BF, Creus GJ. An analytical-numerical framework for the study of ageing in fibre reinforced polymer composites. Composite Structures. 2004;65(3-4):443-57.

[21] Costa I, Barros J. Tensile creep of a structural epoxy adhesive: Experimental and analytical characterization. International Journal of Adhesion and Adhesives. 2015;59(0):115-24.

[22] S\&P. Technical Data Sheet. S\&P Resin 220 epoxy adhesive. S\&P Clever Reinforcement 2013. p. 3.

[23] Correia L, Teixeira T, Michels J, Almeida JA, Sena-Cruz J. Flexural behaviour of RC slabs strengthened with prestressed CFRP strips using different anchorage systems. Composites Part B: Engineering. 2015;81:158-70.

[24] Costa I. Prestressed Carbon Fibre laminates applied according to Near Surface Mounted technique to increase the flexural resistance of Reinforced Concrete beams: University of Minho; 2014.

[25] ISO. ISO 899-1:2003 Plastics - Determination of creep behaviour - Part 1: Tensile creep. Genève, Switzerland: International Organization for Standardization; 2003. p. 15.

[26] ASTM. ASTM D2990-09 Standard Test Methods for Tensile, Compressive, and Flexural Creep and CreepRupture of Plastics. American Society for Testing and Materials; 2009.

[27] Silva J, Azenha M, Correia AG, Ferreira C. Continuous stiffness assessment of cement-stabilised soils from early age. Géotechnique. 2013;63(16):1419-32.

[28] Findley WN, Davis FA. Creep and relaxation of nonlinear viscoelastic materials: Courier Corporation; 2013.

[29] Bažant ZP, Osman E. Double power law for basic creep of concrete. Mat Constr. 1976;9(1):3-11.

[30] FIB. Model Code 1990. International Federation for Structural Concrete (fib); 1990.

[31] Bazant ZP, Wu ST. Dirichlet series creep function for aging concrete. Journal of engineering mechanics. 1973;99(em2).

[32] Bažant ZP, Chern J-C. Log double power law for concrete creep. 1985.

[33] Bažant ZP, L'Hermite R. Mathematical modeling of creep and shrinkage of concrete: Wiley New York; 1988.

[34] Mathworks. Matlab.

[35] Gilbert RI, Ranzi G. Time-dependent behaviour of concrete structures: Taylor \& Francis; 2010.

[1] Pellegrino C, Sena-Cruz J. Design Procedures for the Use of Composites in Strengthening of Reinforced Concrete Structures. State-of-the-Art Report of the RILEM Technical Committee 234-DUC. RILEM State Art Reports. 2015;19.

[2] Hollaway LC, Leeming M. Strengthening of reinforced concrete structures: Using externally-bonded FRP composites in structural and civil engineering: Elsevier; 1999.

[3] Sena-Cruz JB, J.; Bianco, V.; Bilotta, A.; Bournas, D.; Ceroni, F.; Dalfré, G.; Kotynia, R.; Monti, G.; Nigro, E.; Triantafillou, T. Design Procedures for the Use of Composites in Strengthening of Reinforced Concrete Structures: State-of-the-art Report of the RILEM Technical Committee 234-DUC: Springer; 2015.

[4] Sena-Cruz JM, Barros JA, Coelho MR, Silva LF. Efficiency of different techniques in flexural strengthening of RC beams under monotonic and fatigue loading. Construction and Building Materials. 2012;29:175-82.

[5] Feng CW, Keong CW, Hsueh YP, Wang YY, Sue HJ. Modeling of long-term creep behavior of structural epoxy adhesives. International Journal of Adhesion and Adhesives. 2005;25(5):427-36.

[6] Meyers MA, Chawla KK. Mechanical behavior of materials: Cambridge university press Cambridge; 2009.

[7] Schenck SC, Sancaktar E. Material Characterization of Structural Adhesives in the Lap Shear Mode. DTIC Document; 1983.

[8] Smith ST, Hu S, Kim SJ, Seracino R. FRP-strengthened RC slabs anchored with FRP anchors. Engineering Structures. 2011;33(4):1075-87.

[9] Guedes RM. Creep and Fatigue in Polymer Matrix Composites: Woodhead Publishing Limited; 2011.

[10] Costa I, Barros JAO. Creep of structural adhesives : an overview. In: Proceedings of CICE 2012 6th International Conference on FRP Composites in Civil Engineering. Rome, Conference, Conference 2012.

[11] Silva P, Fernandes P, Sena-Cruz J, Xavier J, Castro F, Soares D, et al. Effects of different environmental conditions on the mechanical characteristics of a structural epoxy. Composites Part B: Engineering. 2016;88:5563.

[12] Fernandes P, Granja JL, Benedetti A, Sena-Cruz J, Azenha M. Quality control and monitoring of NSM CFRP systems: E-modulus evolution of epoxy adhesive and its relation to the pull-out force. Composites Part B: Engineering. 2015;75(0):95-103.

[13] Moussa O, Vassilopoulos AP, de Castro J, Keller T. Early-age tensile properties of structural epoxy adhesives subjected to low-temperature curing. International Journal of Adhesion and Adhesives. 2012;35:9-16.

[14] Michels J, Sena-Cruz J, Czaderski C, Motavalli M. Structural strengthening with prestressed CFRP strips with gradient anchorage. Composites for Construction (Aceite para publicação). 2013. 
[15] Rezazadeh M, Costa I, Barros J. Influence of prestress level on NSM CFRP laminates for the flexural strengthening of RC beams. Composite Structures. 2014;116:489-500.

[16] Moussa O, Vassilopoulos AP, Keller T. Effects of low-temperature curing on physical behavior of cold-curing epoxy adhesives in bridge construction. International Journal of Adhesion and Adhesives. 2012;32(0):15-22.

[17] Majda P, Skrodzewicz J. A modified creep model of epoxy adhesive at ambient temperature. International Journal of Adhesion and Adhesives. 2009;29(4):396-404.

[18] Meshgin P, Choi K-K, Reda Taha MM. Experimental and analytical investigations of creep of epoxy adhesive at the concrete-FRP interfaces. International Journal of Adhesion and Adhesives. 2009;29(1):56-66.

[19] Brinson HF, Brinson LC. Polymer engineering science and viscoelasticity: an introduction: Springer; 2008.

[20] Oliveira BF, Creus GJ. An analytical-numerical framework for the study of ageing in fibre reinforced polymer composites. Composite Structures. 2004;65(3-4):443-57.

[21] Costa I, Barros J. Tensile creep of a structural epoxy adhesive: Experimental and analytical characterization. International Journal of Adhesion and Adhesives. 2015;59(0):115-24.

[22] S\&P. Technical Data Sheet. S\&P Resin 220 epoxy adhesive. S\&P Clever Reinforcement 2013. p. 3.

[23] Correia L, Teixeira T, Michels J, Almeida JA, Sena-Cruz J. Flexural behaviour of RC slabs strengthened with prestressed CFRP strips using different anchorage systems. Composites Part B: Engineering. 2015;81:158-70.

[24] Costa I. Prestressed Carbon Fibre laminates applied according to Near Surface Mounted technique to increase the flexural resistance of Reinforced Concrete beams: University of Minho; 2014.

[25] ISO. ISO 899-1:2003 Plastics - Determination of creep behaviour - Part 1: Tensile creep. Genève, Switzerland: International Organization for Standardization; 2003. p. 15.

[26] ASTM. ASTM D2990-09 Standard Test Methods for Tensile, Compressive, and Flexural Creep and CreepRupture of Plastics. American Society for Testing and Materials; 2009.

[27] Silva J, Azenha M, Correia AG, Ferreira C. Continuous stiffness assessment of cement-stabilised soils from early age. Géotechnique. 2013;63(16):1419-32.

[28] Findley WN, Davis FA. Creep and relaxation of nonlinear viscoelastic materials: Courier Corporation; 2013.

[29] Bažant ZP, Osman E. Double power law for basic creep of concrete. Mat Constr. 1976;9(1):3-11.

[30] FIB. Model Code 1990. International Federation for Structural Concrete (fib); 1990.

[31] Bazant ZP, Wu ST. Dirichlet series creep function for aging concrete. Journal of engineering mechanics. 1973;99(em2).

[32] Bažant ZP, Chern J-C. Log double power law for concrete creep. 1985.

[33] Bažant ZP, L'Hermite R. Mathematical modeling of creep and shrinkage of concrete: Wiley New York; 1988.

[34] Mathworks. Matlab.

[35] Gilbert RI, Ranzi G. Time-dependent behaviour of concrete structures: Taylor \& Francis; 2010. 
Silva, P.; Valente, T.; Sena-Cruz, J.; Azenha, M.; Barros, J. (2017) "Viscoelastic response of an epoxy adhesive for construction since its early ages: experiments and modelling." Composites Part B, 116: 266-277. DOI: 10.1016/j.compositesb.2016.10.047

\section{List of tables}

Table 1 - Properties of tensile creep and direct tensile tests.

Table 2 - Results of the tensile tests at different ages.

Table 3 - Relevant data of the tensile creep tests.

Table 4 - Properties of Modified Burgers model.

Table 5 - Outline of the developed algorithm to determine the defining coefficients of the model.

Table 6 - Defining coefficients of the analytical model derived from the proposed framework.

Table 7 - Estimated moduli of the Kelvin chains of the analytical model. 
Silva, P.; Valente, T.; Sena-Cruz, J.; Azenha, M.; Barros, J. (2017) "Viscoelastic response of an epoxy adhesive for construction since its early ages: experiments and modelling." Composites Part B, 116: 266-277. DOI: 10.1016/j.compositesb.2016.10.047

Table 1 - Properties of tensile creep and direct tensile tests.

\begin{tabular}{|c|c|c|c|c|}
\hline \multicolumn{3}{|c|}{ Creep tests } & \multicolumn{2}{|c|}{ Direct tensile tests } \\
\hline Specimens ID & $\begin{array}{c}\% \text { of ultimate load } \\
\text { applied }\end{array}$ & $\begin{array}{c}\text { Age of specimens } \\
\text { at the loading } \\
\text { [days] }\end{array}$ & $\begin{array}{c}\text { Specimens ID } \\
\text { (at age of loading) }\end{array}$ & $\begin{array}{c}\text { Specimens ID } \\
\text { (at age of } \\
\text { unloading) }\end{array}$ \\
\hline C30_D1 & \multirow{4}{*}{$30 \%$} & 1 & DT_D1 & \multirow{4}{*}{ DT_D57 } \\
\hline C30_D2 & & 2 & DT_D2 & \\
\hline C30_D3 & & 3 & DT_D3 & \\
\hline C30_D7 & & 7 & DT_D7(C30) & \\
\hline C40_D7_A & \multirow{2}{*}{$40 \%$} & \multirow{2}{*}{7} & \multirow{2}{*}{ DT_D7(C40) } & \multirow{2}{*}{ DT_D85 } \\
\hline C40_D7_B & & & & \\
\hline
\end{tabular}


Table 2 - Results of the tensile tests at different ages.

\begin{tabular}{ccccccc}
\hline ID & $\begin{array}{c}\text { Age of test } \\
{[\text { days }]}\end{array}$ & $\begin{array}{c}A^{(1)} \\
{\left[\mathrm{mm}^{2}\right]}\end{array}$ & $\begin{array}{c}f_{\text {ult }}(1) \\
{[\mathrm{MPa}]}\end{array}$ & $\begin{array}{c}E_{\text {adh,d }}(1) \\
{[\mathrm{GPa}]}\end{array}$ & $\begin{array}{c}\mathcal{E}_{\mathrm{ult}}(1) \\
{[\%]}\end{array}$ & $\begin{array}{c}E_{\text {adh,num }} \\
{[\mathrm{GPa}]}\end{array}$ \\
\hline DT_D1 & 1 & $45.10(0.6 \%)$ & $18.65(3.2 \%)$ & $3.73(3.8 \%)$ & $0.955(15.6 \%)$ & 3.73 \\
\hline DT_D2 & 2 & $43.93(1.5 \%)$ & $24.17(3.9 \%)$ & $6.99(6.0 \%)$ & $0.496(16.6 \%)$ & 6.91 \\
\hline DT_D3 & 3 & $44.90(0.9 \%)$ & $22.51(3.2 \%)$ & $6.93(2.1 \%)$ & $0.432(9.6 \%)$ & 7.76 \\
\hline DT_D7(C30) & 7 & $45.53(2.6 \%)$ & $24.64(7.5 \%)$ & $8.44(2.2 \%)$ & $0.342(17.7 \%)$ & 8.38 \\
\hline DT_D7(C40) & 7 & $46.06(2.6 \%)$ & $23.06(4.4 \%)$ & $8.27(1.2 \%)$ & $0.313(12.8 \%)$ & 8.38 \\
\hline DT_D57 & 57 & $45.04(2.4 \%)$ & $24.81(3.8 \%)$ & $8.48(4.1 \%)$ & $0.367(14.0 \%)$ & 8.53 \\
\hline DT_D85 & 85 & $44.70(3.7 \%)$ & $25.61(1.4 \%)$ & $8.54(1.0 \%)$ & $0.442(8.4 \%)$ & 8.53 \\
\hline
\end{tabular}

Notes: ${ }^{(1)}$ Average values; the values in parentheses correspond to the coefficient of variation.

Notes: The values in parentheses correspond to the coefficient of variation. 
Table 3 - Relevant data of the tensile creep tests.

\begin{tabular}{ccccc}
\hline ID specimen & $\begin{array}{c}\text { M } \\
{\left[\mathrm{mm}^{2}\right]}\end{array}$ & $\begin{array}{c}M_{\text {applied }} \\
{[\mathrm{kg}]}\end{array}$ & $\begin{array}{c}\sigma_{\text {instal }} \\
{[\mathrm{MPa}]}\end{array}$ & $\begin{array}{c}\% f_{\text {ult }} \\
{[\%]}\end{array}$ \\
\hline C30_D1 & 44.60 & 8.39 & 5.54 & 29.7 \\
\hline C30_D2 & 42.77 & 10.51 & 7.23 & 29.9 \\
\hline C30_D3 & 44.43 & 10.18 & 6.74 & 29.9 \\
\hline C30_D7 & 44.76 & 11.21 & 7.37 & 39.9 \\
\hline C40_D7_A & 45.98 & 14.38 & 9.19 & 40.0 \\
\hline
\end{tabular}


Table 4 - Properties of Modified Burgers model.

\begin{tabular}{ccccccc}
\hline Specimen ID & $\begin{array}{c}E_{\mathrm{M}} \\
{[\mathrm{MPa}]}\end{array}$ & $\begin{array}{c}\eta_{\mathrm{M}} \\
{[\mathrm{h}]}\end{array}$ & $\begin{array}{c}E_{\mathrm{k}} \\
{[\mathrm{MPa}]}\end{array}$ & $\begin{array}{c}t_{\mathrm{r}} \\
{[\mathrm{h}]}\end{array}$ & $\begin{array}{c}\eta_{\mathrm{k}} \\
{[\mathrm{MPa} \cdot \mathrm{h}]}\end{array}$ & $n$ \\
\hline C30_D1 & 3683.13 & 55358076 & 907.96 & 2 & 1815.92 & 0.396 \\
\hline C30_D2 & 5954.36 & 72289649 & 3162.36 & 5.67 & 17920.06 & 0.529 \\
\hline C30_D3 & 6680.41 & 33687978 & 3983.35 & 20.17 & 80330.87 & 0.536 \\
\hline C30_D7 & 8410.11 & 81886754 & 7199.21 & 46.33 & 333563.48 & 0.550 \\
\hline
\end{tabular}


Table 5 - Outline of the developed algorithm to determine the defining coefficients of the model.

Input:

- $\left[t_{j, i}, J\left(t_{j, i}, t_{0, i}\right)\right](i=1, \ldots, L)\left(j=1, \ldots, M_{L}\right)$ : array of discrete values of time and creep compliance;

- $\quad N$ : number of Kelvin chains to be considered;

- $\tau_{\mu}(\mu=1, \ldots, N)$ : retardation time of each Kelvin chain;

- $t_{o, i}(i=1, \ldots, L)$ : loading ages;

- $\quad E_{0, i}(i=1, \ldots, L)$ : elasticity modulus for each of the considered loading ages;

- $\lambda$ : coefficient to be multiplied by $E_{0, i}$

- $\psi_{0}$ (initial values of the defining coefficients);

- $T O L E R_{1}$ : Termination tolerance on the objective function

- $T O L E R_{2}$ : Termination tolerance on the variation of the defining values

Output: $\psi$ (defining coefficients of the model)

i) Initialization of iteration counter $p=1$; set $\psi_{p}=\psi_{0}$.

ii) Compute $\overline{J_{p}}\left(t_{j, i}, t_{0, i}\right)$ for $\left(j=1, \ldots, M_{L}\right)$, based on $\psi_{p}$, following equations (4-7).

iii) Compute objective function: $\Phi=\sum_{i=1}^{L} \sum_{j=1}^{M_{L}}\left(J\left(t_{j, i}, t_{0, i}\right)-\left(\bar{J}\left(t_{j, i}, t_{0, i}\right)\right)\right)^{2}$.

iv) Check termination criteria of the objective function:

$$
\begin{array}{ll}
\text { Is } \Phi_{p} \leq T O L E R_{1} ? & \text { Yes: End. } \\
& \text { No: Go to v). }
\end{array}
$$

v) Iteration counter update:
Is $p \leq$ MAXITER
Yes: Go to ii).

No: End.

vi) Define value of $\psi_{p}$ for new iteration, based on NLSM method.

vii) Check termination criteria of the variation of $\psi_{p}$ :
Is $\psi_{p}-\psi_{p-1} \leq$ TOLER $R_{2}$ ?
Yes: End.
No: Go to ii). 
Table 6 - Defining coefficients of the analytical model derived from the proposed framework.

\begin{tabular}{ccccccc}
\hline & & \multicolumn{5}{c}{ Kelvin chains $\mu$} \\
Coefficients & $\mu=1$ & $\mu=2$ & $\mu=3$ & $\mu=4$ & $\mu=5$ & $\mu=6$ \\
\hline $\boldsymbol{b}_{\boldsymbol{\mu}}$ & $1.424 \mathrm{E}+00$ & $8.000 \mathrm{E}-01$ & $8.569 \mathrm{E}-01$ & $8.249 \mathrm{E}-01$ & $8.589 \mathrm{E}-01$ & $8.903 \mathrm{E}-01$ \\
\hline $\boldsymbol{n}_{\boldsymbol{\mu}}$ & $6.433 \mathrm{E}-01$ & $-1.249 \mathrm{E}+01$ & $4.646 \mathrm{E}-01$ & $-8.352 \mathrm{E}-03$ & $-1.338 \mathrm{E}-01$ & $-1.286 \mathrm{E}-01$ \\
\hline $\boldsymbol{m}_{\boldsymbol{\mu}}$ & $2.925 \mathrm{E}-01$ & $9.696 \mathrm{E}-03$ & $9.883 \mathrm{E}-01$ & $1.073 \mathrm{E}-01$ & $-1.573 \mathrm{E}-01$ & $-2.415 \mathrm{E}-01$ \\
\hline $\boldsymbol{\varphi}_{\mathbf{1 , \mu}}$ & $1.424 \mathrm{E}+00$ & $3.660 \mathrm{E}-01$ & $8.569 \mathrm{E}-01$ & $8.248 \mathrm{E}-01$ & $8.589 \mathrm{E}-01$ & $8.903 \mathrm{E}-01$ \\
\hline
\end{tabular}


Table 7 - Estimated moduli of the Kelvin chains of the analytical model.

\begin{tabular}{cccccccc}
\hline \multirow{2}{*}{$\begin{array}{c}\boldsymbol{t}_{\mathbf{0}, \boldsymbol{i}} \\
\text { [days }]\end{array}$} & $\boldsymbol{E}\left(\boldsymbol{t}_{\mathbf{0}, \boldsymbol{i}}\right)$ & \multicolumn{5}{c}{$\boldsymbol{E}_{\boldsymbol{\mu}}\left(\boldsymbol{t}_{\mathbf{0}, \boldsymbol{i}}\right)[\mathrm{MPa}]$} \\
\cline { 3 - 8 } & {$[\mathrm{MPa}]$} & $\mu=1$ & $\mu=2$ & $\mu=3$ & $\mu=4$ & $\mu=5$ & $\mu=6$ \\
\hline $\mathbf{1}$ & $5.598 \mathrm{E}+03$ & $4.314 \mathrm{E}+03$ & $1.025 \mathrm{E}+13$ & $1.238 \mathrm{E}+03$ & $8.666 \mathrm{E}+03$ & $2.373 \mathrm{E}+04$ & $2.367 \mathrm{E}+04$ \\
\hline $\mathbf{2}$ & $1.049 \mathrm{E}+04$ & $9.994 \mathrm{E}+03$ & $1.933 \mathrm{E}+13$ & $4.754 \mathrm{E}+03$ & $1.755 \mathrm{E}+04$ & $3.965 \mathrm{E}+04$ & $3.721 \mathrm{E}+04$ \\
\hline $\mathbf{3}$ & $1.040 \mathrm{E}+04$ & $1.106 \mathrm{E}+04$ & $1.924 \mathrm{E}+13$ & $6.839 \mathrm{E}+03$ & $1.812 \mathrm{E}+04$ & $3.706 \mathrm{E}+04$ & $3.370 \mathrm{E}+04$ \\
\hline $\mathbf{7}$ & $1.265 \mathrm{E}+04$ & $1.724 \mathrm{E}+04$ & $2.361 \mathrm{E}+13$ & $1.920 \mathrm{E}+04$ & $2.415 \mathrm{E}+04$ & $3.948 \mathrm{E}+04$ & $3.343 \mathrm{E}+04$ \\
\hline
\end{tabular}


Silva, P.; Valente, T.; Sena-Cruz, J.; Azenha, M.; Barros, J. (2017) "Viscoelastic response of an epoxy adhesive for construction since its early ages: experiments and modelling." Composites Part B, 116: 266-277. DOI: 10.1016/j.compositesb.2016.10.047

\section{List of figures}

Figure 1 - Specimen and creep test: (a) Specimen's geometry (all units are in millimetres); (b) photo of specimen in creep test (c) Tensile creep test overview; (d) front view of lever system; and, (e) top view of creep test table.

Figure 2 - Stress versus strain obtained from tensile tests at different ages corresponding to the creep tests with a stress level of: (a) $30 \%$; (b) $40 \%$.

Figure 3 - Creep tests at different ages: (a) specimens loaded at 1, 2, 3 and 7 days of age at $30 \%$ of $f_{u l t}$; (b) detail of creep response at 1,2 and 3 days of age.

Figure 4 - Creep tests of specimens loaded at 7 days of age: (a) creep strain and recovery of specimens loaded at $40 \%$ of $f_{u l t} ;$ (b) creep compliance.

Figure 5 - Analytical responses of Modified Burgers model versus experimental results.

Figure 6 - Schematic representation of the Generalized Kelvin model.

Figure 7 - Example of three creep functions $(\mathrm{L}=3)$ to be fitted, where each function is defined by different number of points: $\mathrm{M}_{1}=10 ; \mathrm{M}_{2}=8 ; \mathrm{M}_{3}=7$.

Figure 8 - Comparison between the creep compliance derived from the experimental tests and from the analytical model.

Figure 9 - The relaxation spectra for various loading ages.

Figure 10 - Comparison between the experimental creep tests strain and its analytical simulation.

Figure 11 - Creep compliance derived from the experimental tests and from the analytical model: (a) Fitting with 1, 2 and 3 days of age and estimation of the creep compliance for $t_{0}=7$ days; and (b) Fitting with 1,2 and 7 days of age and estimation of the creep compliance for $\mathrm{t}_{0}=3$ days. 


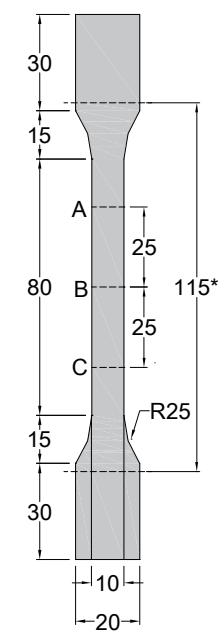

(a)

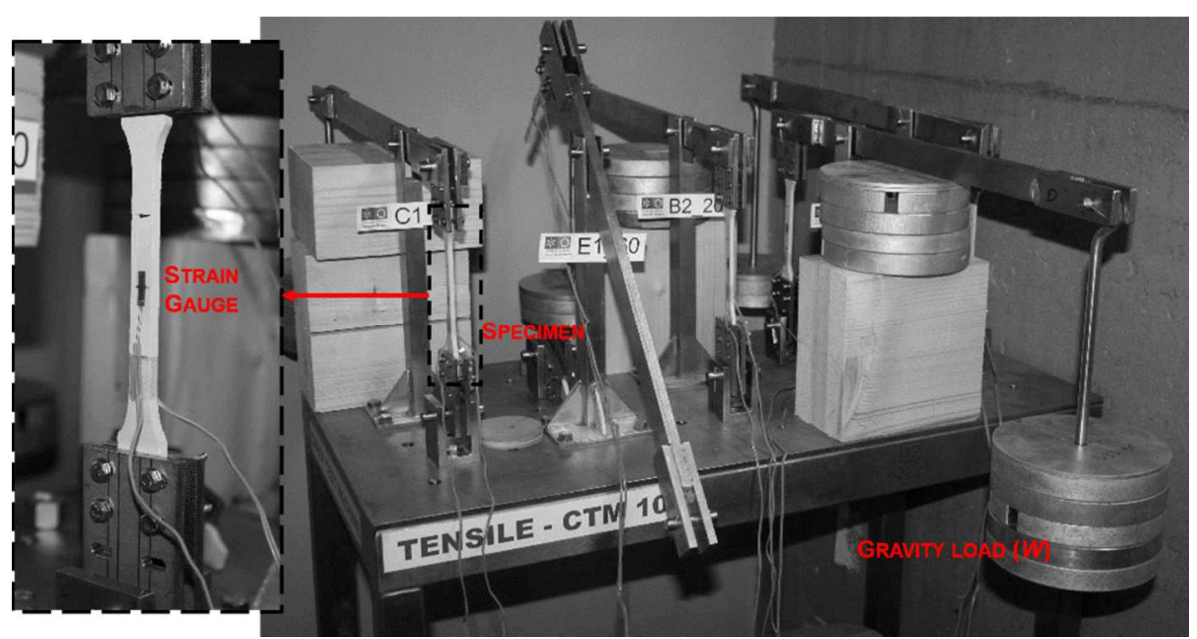

(b)

(c)

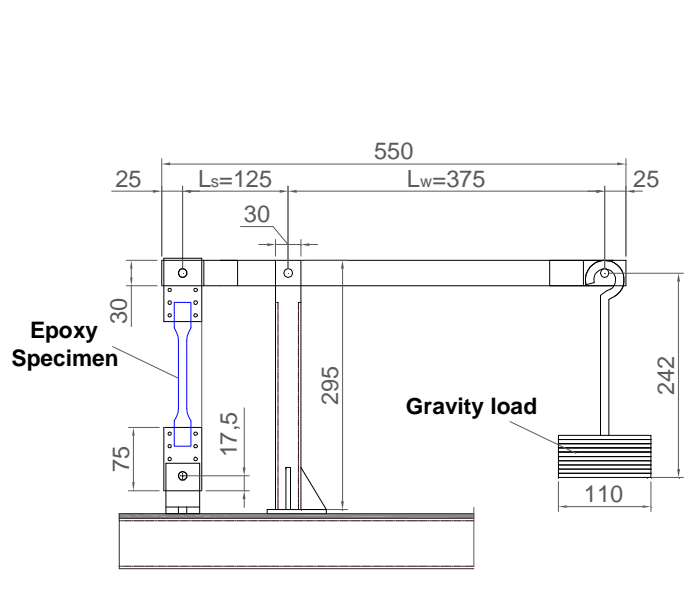

(d)

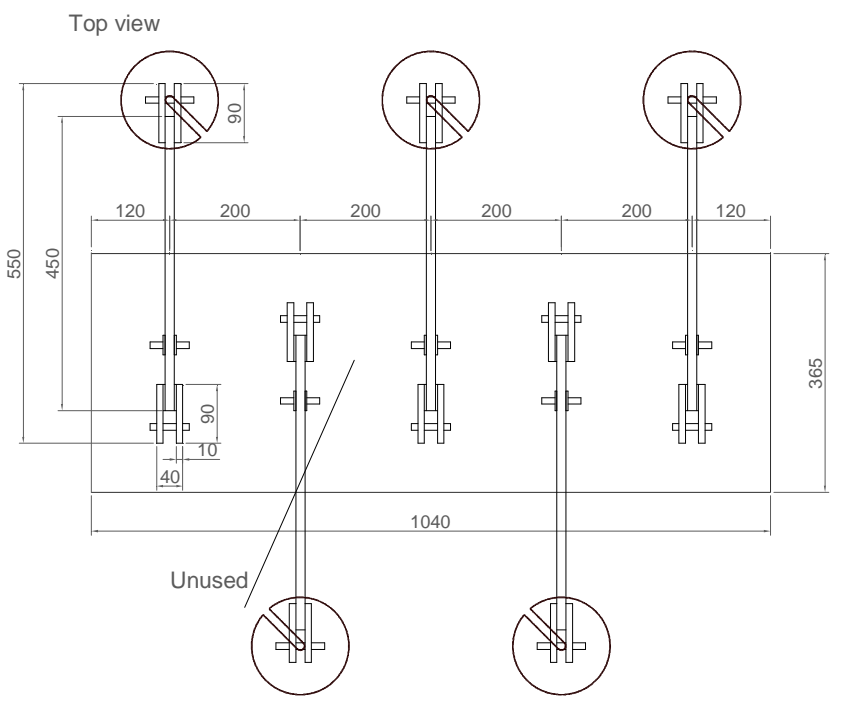

(e)

Figure 1 - Specimen and creep test: (a) Specimen's geometry (all units are in millimetres); (b) photo of specimen in creep test (c) Tensile creep test overview; (d) front view of lever system; and, (e) top view of creep test table. 


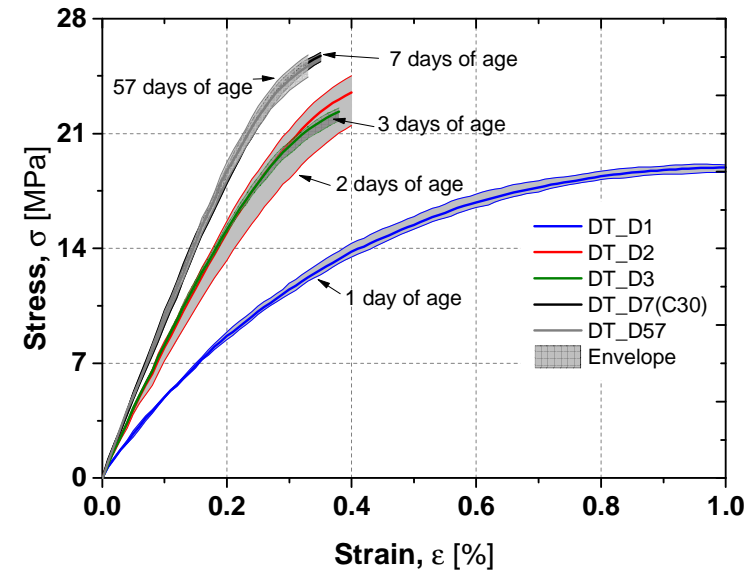

(a)

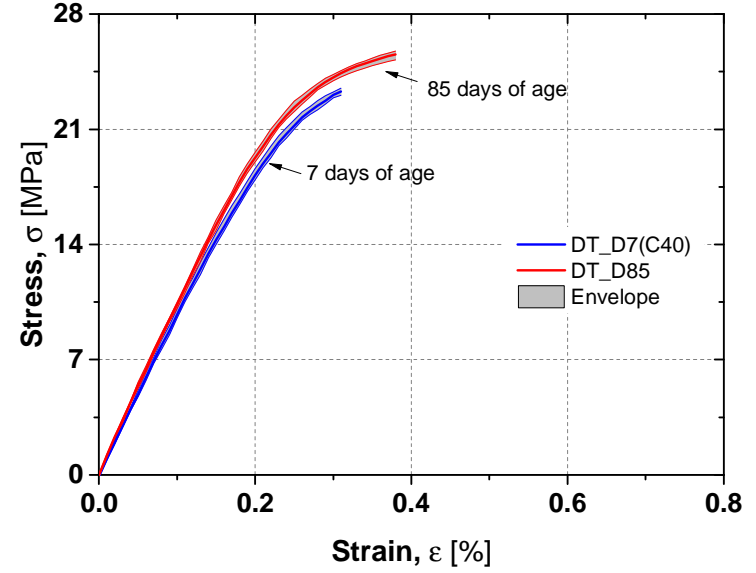

(b)

Figure 2 - Stress versus strain obtained from tensile tests at different ages corresponding to the creep tests with a stress level of: (a) 30\%; (b) $40 \%$. 


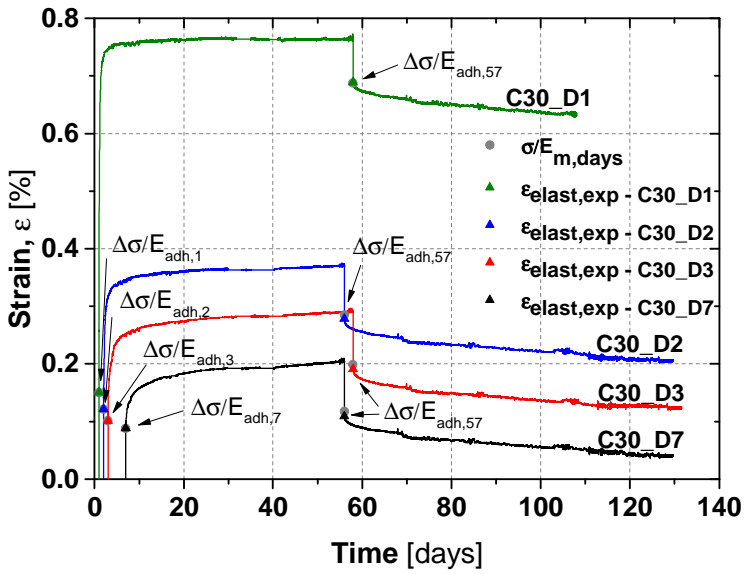

(a)

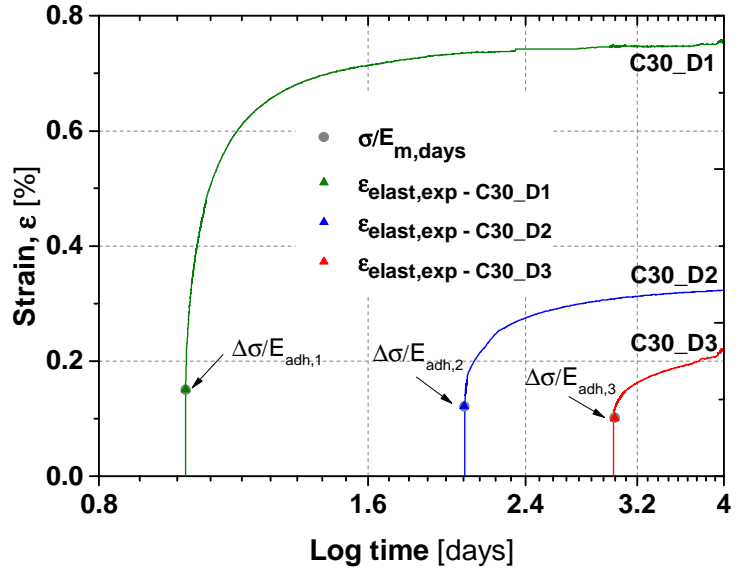

(b)

Figure 3 - Creep tests at different ages: (a) specimens loaded at 1, 2, 3 and 7 days of age at $30 \%$ of $f_{u l t}$; (b) detail of creep response at 1,2 and 3 days of age. 


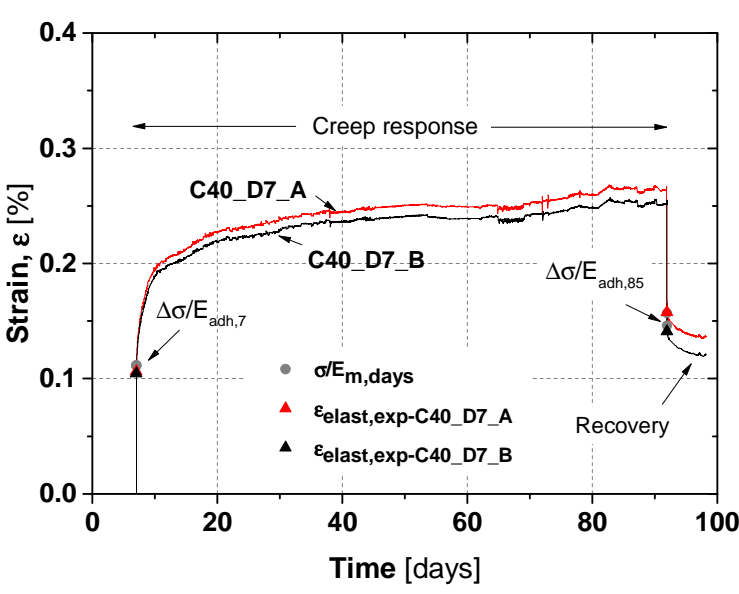

(a)

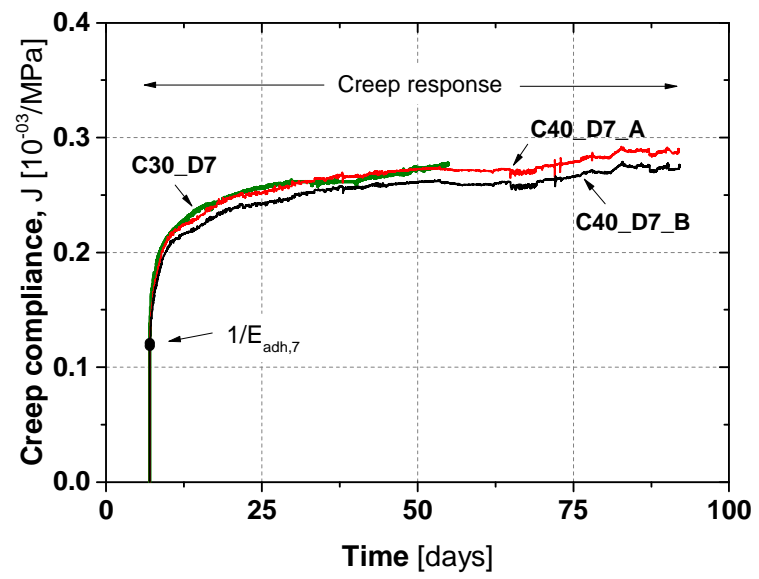

(b)

Figure 4 - Creep tests of specimens loaded at 7 days of age: (a) creep strain and recovery of specimens loaded at $40 \%$ of $f_{u l t}$; (b) creep compliance. 


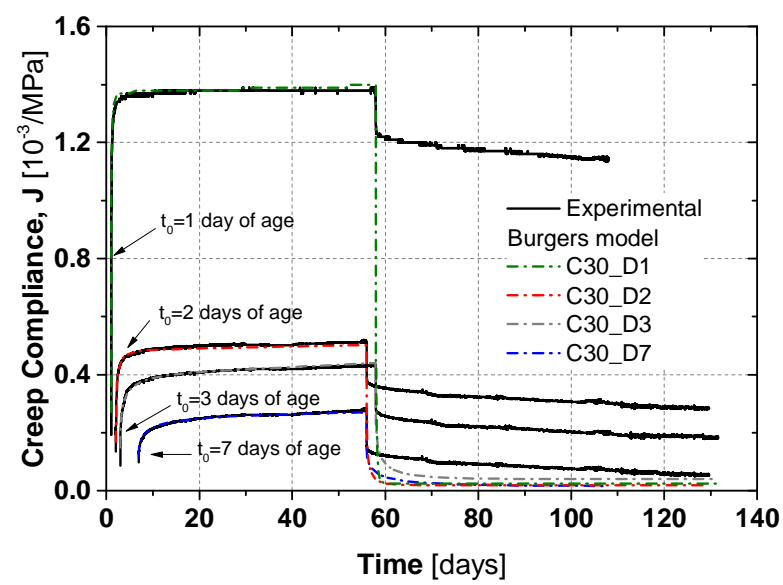

Figure 5 - Analytical responses of Modified Burgers model versus experimental results. 


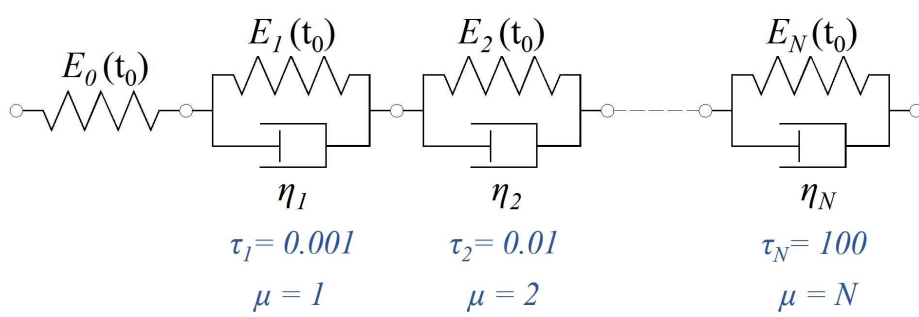

Figure 6 - Schematic representation of the Generalized Kelvin model. 


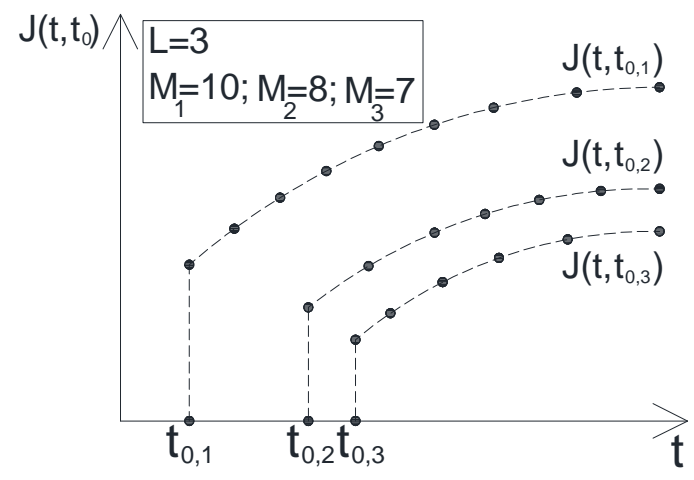

Figure 7 - Example of three creep functions $(\mathrm{L}=3)$ to be fitted, where each function is defined by different number of points: $M_{1}=10 ; M_{2}=8 ; M_{3}=7$. 


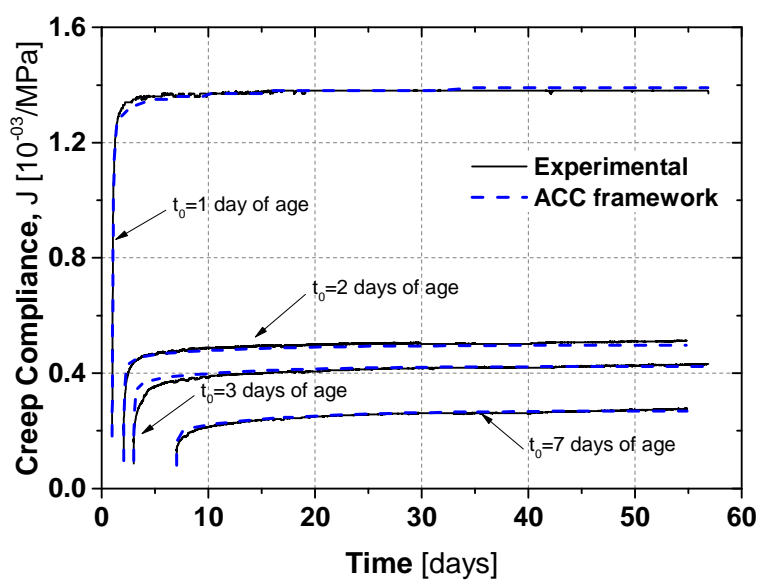

Figure 8 - Comparison between the creep compliance derived from the experimental tests and from the analytical model. 


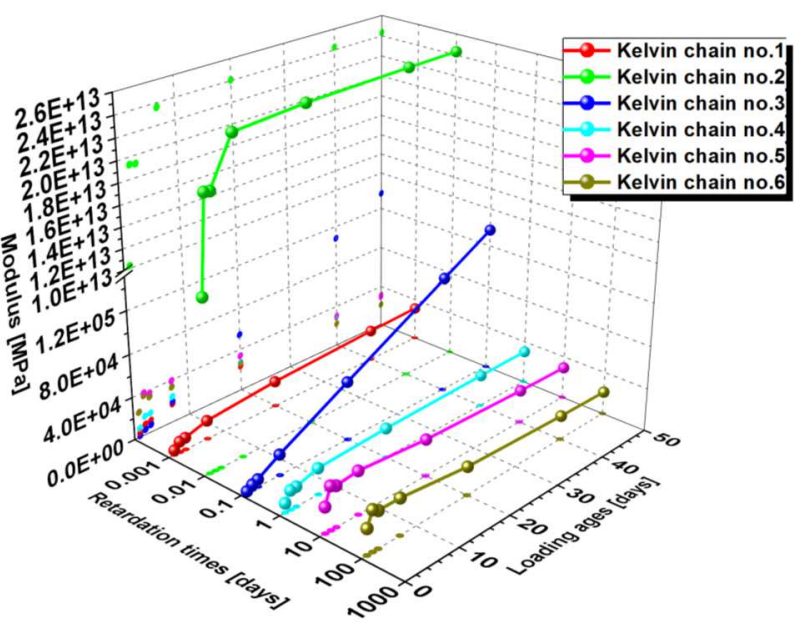

Figure 9 - The relaxation spectra for various loading ages. 


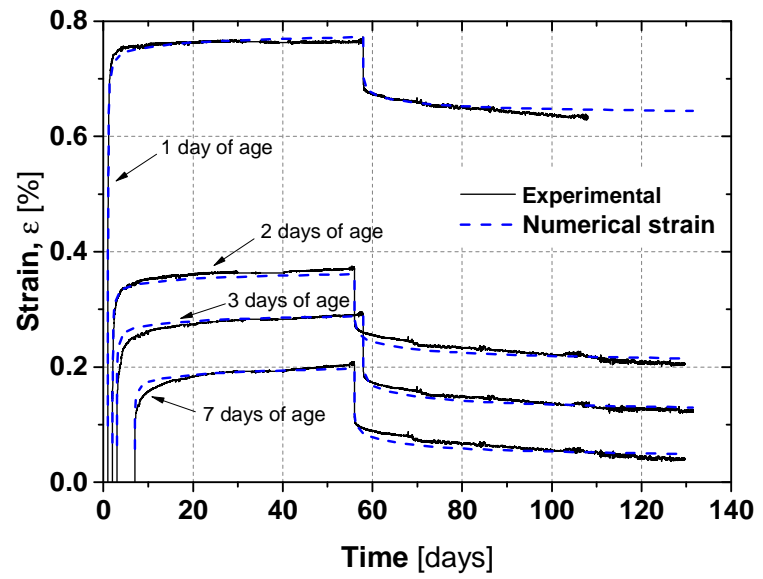

Figure 10 - Comparison between the experimental creep tests strain and its analytical simulation. 


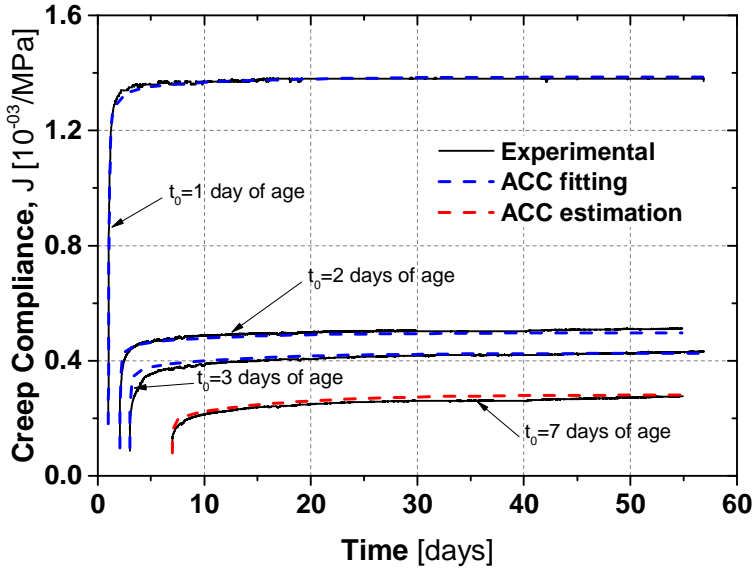

(a)

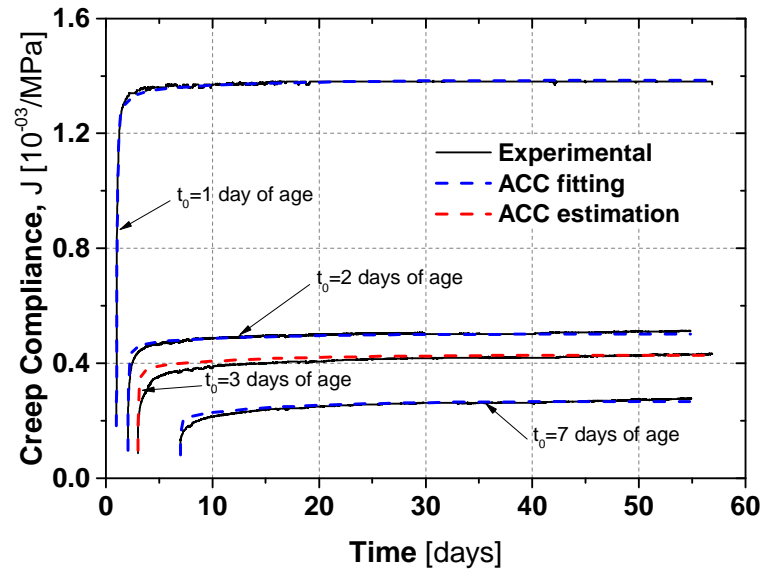

(b)

Figure 11 - Creep compliance derived from the experimental tests and from the analytical model: (a) Fitting with 1, 2 and 3 days of age and estimation of the creep compliance for $t_{0}=7$ days; and (b) Fitting with 1,2 and 7 days of age and estimation of the creep compliance for $\mathrm{t}_{0}=3$ days. 